\title{
Papers
}

\section{Promoting urinary continence in women after delivery: randomised controlled trial}

\author{
Pauline Chiarelli, Jill Cockburn
}

\begin{abstract}
Objectives To test the effectiveness of a physiotherapist delivered intervention designed to prevent urinary incontinence among women three months after giving birth.

Design Prospective randomised controlled trial with women randomised to receive the intervention (which entailed training in pelvic floor exercises and incorporated strategies to improve adherence) or usual postpartum care.

Setting Postpartum wards of three tertiary teaching hospitals in the Hunter region, New South Wales, Australia.

Participants Women who had forceps or ventouse deliveries or whose babies had a high birth weight $(\geqslant 4000 \mathrm{~g})$, or both -676 (348 in the intervention group and 328 in the usual care group) provided endpoint data at three months.

Main outcome measures Urinary incontinence at three months measured as a dichotomous variable. The severity of incontinence was also measured. Self report of the frequency of performance of pelvic floor exercises was recorded.

Results At three months after delivery, the prevalence of incontinence in the intervention group was 31.0\% (108 women) and in the usual care group 38.4\% (125 women); difference 7.4\% (95\% confidence interval $0.2 \%$ to $14.6 \%, \mathrm{P}=0.044)$. At follow up significantly fewer women with incontinence were classified as severe in the intervention group (10.1\%) $v(17.0 \%)$, difference $7.0 \%, 1.6 \%$ to $11.8 \%$ ). The proportions of women reporting doing pelvic floor exercises at adequate levels was $84 \%$ ( $80 \%$ to $88 \%)$ for the intervention group and $58 \%$ (52\% to $63 \%$ ) for the usual care group $(\mathrm{P}=0.001)$.

Conclusions The intervention promoting urinary continence reduced the prevalence of urinary incontinence after giving birth, particularly its severity, and promoted the performance of pelvic floor exercises at adequate levels; both continence and adherence to the programme were measured at three months after delivery in women who had forceps or ventouse deliveries or babies weighing $4000 \mathrm{~g}$ or more.
\end{abstract}

\section{Introduction}

Urinary incontinence is a major clinical problem that has a profound effect on quality of life and activities of daily living. ${ }^{1-3}$ It is physically debilitating and socially incapacitating, with loss of self confidence, feelings of helplessness, depression, and anxiety all related to its occurrence. ${ }^{45}$ The prevalence among women increases during young adult life: a recent study of over 40000 women in the community estimated a prevalence of $12.8 \%$ in women aged $18-22,36.1 \%$ in women aged $40-49$, and $35.0 \%$ in women aged $70-74{ }^{6}$

Urinary incontinence is also costly. One US study reported costs of $\$ 26.3 \mathrm{bn}$ ( $£ 18.4 \mathrm{bn}, € 27.1 \mathrm{bn}$ ) in 1995 for people aged 65 and older. ${ }^{7}$ Another recent report estimated that 1835628 women in the community older than 18 had urinary incontinence in 1998, which incurred a total annual cost of A $\$ 710.4 \mathrm{~m}(£ 257.7 \mathrm{~m}$, US $\$ 367.4 \mathrm{~m}, € 422.5 \mathrm{~m}$ ). Extrapolating these data 20 years gives a total projected cost of $\mathrm{A} \$ 1267.9 \mathrm{~m}$, of which A $\$ 1.2 \mathrm{bn}(93 \%)$ would constitute costs associated with incontinent women aged over $40 .{ }^{8}$

Although studies have proved that conservative treatment of urinary incontinence is effective, we could find no studies on preventing incontinence before its symptoms become evident. ${ }^{9}{ }^{10}$ Epidemiological studies have shown an association between more severe forms of urinary incontinence and assisted vaginal deliveries or deliveries of infants with a high birth weight, which suggests the potential for an intervention promoting continence that is targeted at women who have just given birth. ${ }^{11}{ }^{12}$

Our study aimed to test the effectiveness of a programme for preventing urinary incontinence in women at three months after delivery. The intervention incorporated exercises to strengthen the pelvic floor and established principles of health promotion to encourage adherence to the programme. The study hypothesis was that, in a randomised controlled trial of an intervention that promoted continence and was delivered by physiotherapists, the prevalence of urinary incontinence among women in the intervention group would be lower than among women in the usual care group.

\section{Methods}

The study, a randomised controlled trial, was conducted in the postpartum wards of three hospitals

\section{Faculty of Health, School of \\ Population Health Sciences, University of Newcastle, Box 24, Callaghan, NSW 2308, Australia Pauline Chiarelli senior lecturer physiotherapy Jill Cockburn professor of behavioural science in relation to medicine \\ Correspondence to: P Chiarelli Pauline.Chiarelli@ newcastle.edu.au \\ bmj.com 2002;324:1241}


in the Hunter region, New South Wales, Australia. These were a 580 bed metropolitan public teaching hospital with 3208 births a year, a 68 bed metropolitan private hospital with 962 births a year, and a 170 bed rural public hospital with 1150 births a year. Data were collected between August 1998 and February 2000. Ethics committees of the Hunter area health service and the University of Newcastle granted approval for this study. Women were eligible to join if they had had forceps or ventouse deliveries or their babies had had a birth weight of $4000 \mathrm{~g}$ or more.

\section{Sample size calculation}

The estimated prevalence of urinary incontinence after delivery is $7-30 \%{ }^{13-15}$; for sample size calculation we assumed a prevalence of $30 \%$. To detect a $10 \%$ difference between intervention and control groups at $\alpha=0.05$ and $\beta=0.80$, and using the formula given by Pocock for two sided comparisons, a final sample of 290 women who fitted the criteria was required in each group. $^{16}$ The reduction of incontinence from a prevalence of $30 \%$ to $20 \%$ corresponds to an odds ratio of 0.58 . Allowing for a $20 \%$ dropout, we needed to recruit about 350 women in each group.

\section{Development of the intervention}

The intervention was multifaceted and is shown in figure 1 . The intervention was underpinned by the framework of the health belief model (http://hsc.usf. edu/ kmbrown/Health_Belief_Model_Overview.htm), included strategies to improve compliance, and was developed by using a consensus of expert opinion and input from women in the target group. ${ }^{17-19}$ Compliance

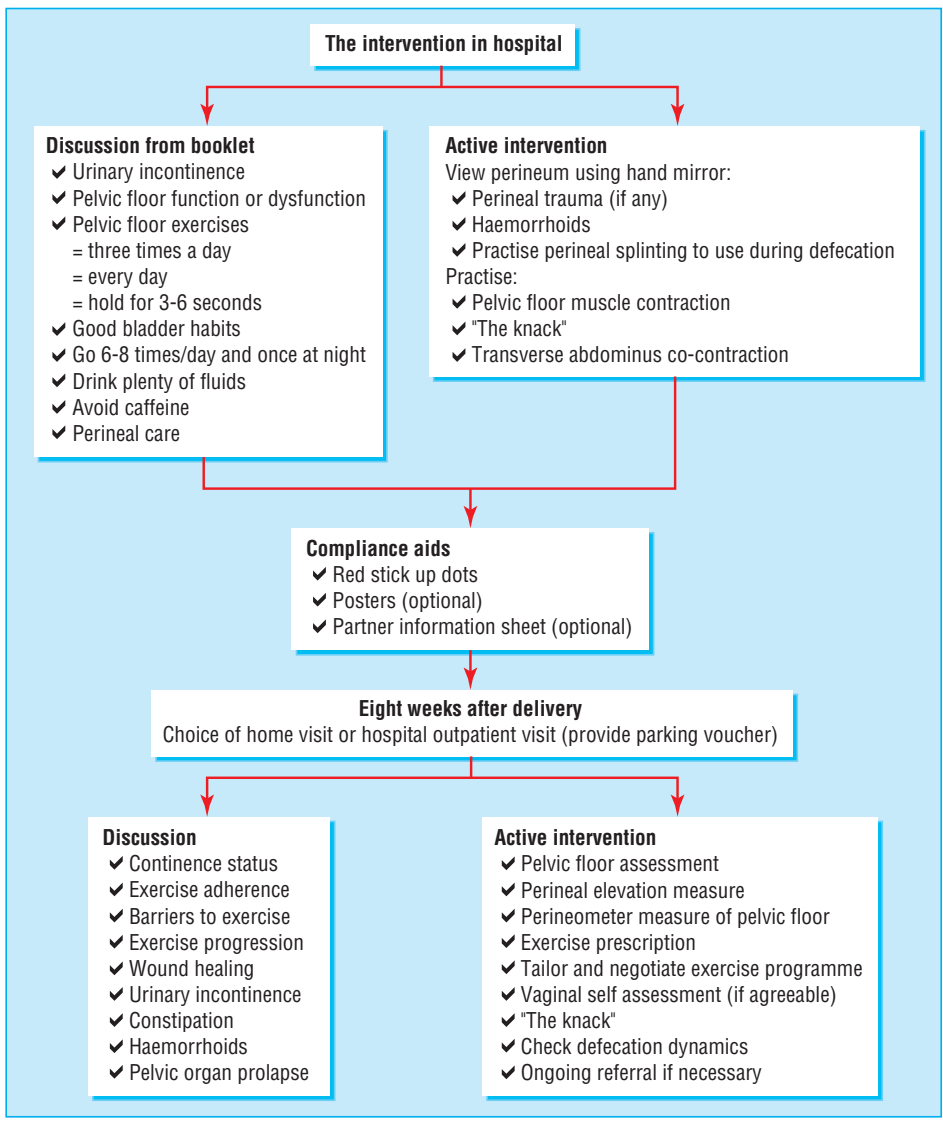

Fig 1 Components of intervention promoting continence strategies included tailoring the exercise programme to the functional abilities of each woman's pelvic floor muscles and negotiating with the woman about the most convenient times for her to carry out her exercises. Each woman was given a poster and sticky red dots to place in relevant places (to serve as reminders to do the exercises) and was offered an information sheet for her partner. Similar techniques from social marketing and health promotion were used to develop an eight page, A4, bifold booklet designed specifically for this intervention. This booklet included information about pelvic floor exercises, educational material about the function and structure of the pelvic floor, the effects of childbirth on the pelvic floor, perineal care, good bladder habits, and instructions about avoiding constipation. All diagrams and the text used in the booklet were pretested to ensure readability, acceptability, and relevance to the target group.

\section{Collection of baseline data in hospital}

Eligible women were approached on the ward by one of three physiotherapists, usually within 48 hours of delivery. Consenting women completed a structured interview that elicited information on sociodemographics and experiences of urinary incontinence before the pregnancy and after delivery. After this, women were randomised to either a control group receiving usual care or the group receiving the intervention. A computer generated randomisation list contained the identification numbers for women in the trial. The allocation to intervention or control group was placed by a research assistant in a sealed opaque envelope marked with the corresponding study identification number. The physiotherapists were blinded to the woman's allocation until the structured interview was completed. At this point, the envelope was opened and the woman was told that she had been allocated (by chance) to either the intervention or the usual care group.

\section{Intervention group}

The women randomised to the intervention group were seen by the physiotherapist once during their stay in hospital and 306 women were seen again for a single visit with the same physiotherapist at eight weeks after delivery. The components of the eight week intervention are shown in figure 1 . The visit occurred at either the hospital (205 (67\%) women) or the woman's home (101 (33\%) women) if transport was a problem. The intervention in hospital required about 20 minutes of the physiotherapist's time, and the follow up visit was completed in about 30 minutes.

\section{Usual care group}

The usual care group received routine postpartum care, which did not include a visit from a physiotherapist. A brochure produced by the hospital was made available to all these women while in hospital. This outlined general postpartum and pelvic floor exercises, along with an invitation to join the routine physiotherapy postnatal classes held in the wards. No restrictions were imposed on women in undertaking any postnatal exercises that they chose to do or were recommended by other healthcare professionals.

\section{Follow up survey}

All participants were interviewed by telephone three months after their recruitment into the study. The 
interviewer was trained by $\mathrm{PC}$ and was blind to the group allocation of the women being interviewed. Women were also sent a bladder diary before this interview.

\section{Measures}

\section{Primary end point}

The primary end point for the study was urinary incontinence at three months measured as a dichotomous variable. In the follow up survey women were asked, "In the past month have you:

- leaked even small amounts of urine when you were coughing, sneezing, laughing, or lifting;

- gone to the toilet urgently for fear you would leak;

- leaked even small amounts if you had to wait to use the toilet;

- leaked even small amounts on your way to the toilet; or

- leaked even small amounts if you hadn't gone to the toilet immediately you first felt the need."

They were classified as incontinent if they responded "occasionally," "often," or "always" to any of the items. The first item in the list relates to stress incontinence whereas the others relate to urge incontinence. ${ }^{20}$ The questions have been shown to be valid when measured against two tests performed at home by women using pads for two hours and for 48 hours and to be acceptable to women immediately after delivery. ${ }^{22}$ The International Continence Society recommends the use of a bladder diary to validate self reported measures. ${ }^{20}$ In our study women completed a three day bladder diary before the follow up survey to improve recall.

\section{Secondary end points}

Severity of incontinence-Women were asked about the frequency and amount of urine loss on the basis of a validated scale that categorised severity as slight, moderate, or severe. ${ }^{23} 24$

Performance of pelvic floor exercises-Women were asked if they were performing pelvic floor exercises. Response options were "never," "less than once weekly," "about once a week" (categorised as inadequate levels), "a couple of times a week," "daily," or "more than once a day" (categorised as adequate levels).

\section{Confounders}

Personal characteristics-Age and body mass index were ascertained from women's medical notes.

Women's other experiences of urinary incontinenceWhile women were still in hospital they were asked if they had experienced urinary incontinence since the baby was born. The response options were "yes," "no," and "don't know." Women who had a urethral catheter in situ were coded as "don't know."

Women were also asked about urinary incontinence at times other than during pregnancy and since the baby was born. If they answered "yes," the five items listed on the self report measure already described were used to determine the type of incontinence that they had experienced.

Perineal status-The perineal status of the women was determined from the birth register as an intact perineum, a graze, a tear (not sutured), a tear with sutures, an episiotomy, or an episiotomy and a tear. If women had a tear with sutures, the degree of the tear (second degree, third degree, fourth degree) was noted.

Collagen status-The collagen status of women was measured in two ways. The first marker was hypermobility as assessed by thumb to wrist hyperabductionthumb to touch wrist, phalangeal hyperextension of the third finger to $90^{\circ}$, and elbow hyperextension beyond $180^{\circ}$. Hypermobility was taken to be present when two of the three measures were positive. The second marker was the presence of abdominal striae and their visual assessment as either mild or marked. ${ }^{25} 26$

Type of delivery-The type of delivery was categorised according to whether instruments were used or not.

\section{Data analysis}

The effectiveness of the intervention was analysed by intention to treat. Logistic regression, using continence status at three months as the outcome measure and including the intervention group as a predictor variable, determined the effect of the intervention while controlling for any residual confounding from variables specified a priori. Mantel-Haenszel $\chi^{2}$ statistics were used to test for a significantly increasing trend in the proportions of women exercising at adequate levels between the intervention and control groups.

\section{Results}

\section{Response rate}

During data collection, 1326 women fitted the description for the reference population and formed the source population for this study (figure 2). Of these women, 913 were approached and 720 consented to take part. This gives a response rate of $54.3 \%$ - the proportion of women in the final sample from the available source population. The consent rate of $78.9 \%$ represents the proportion of women in the sample from the women approached overall.

No significant differences were found between the overall mean age and number of births of the women in the study and women who were missed, transferred out, or not approached to participate. Although the differences in mean age ( 3 years) and mean number of births ( 0.4 births) between the private and public hospitals were statistically significant, they were not considered to be of clinical significance. Women were seen on average on the second day after delivery (range 0-10 days). Only one woman was seen 10 days after delivery. The day after delivery was when most women were seen.

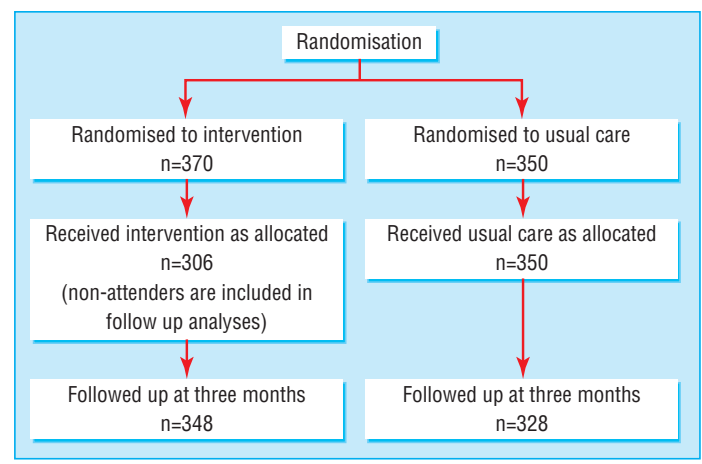

Fig 2 Study procedures 
Table 1 Characteristics of women randomised to receive an intervention designed to prevent urinary incontinence after giving birth and controls. Values are numbers (percentages)

\begin{tabular}{lcc}
\multicolumn{1}{l}{ Intervention (n=348) } & Usual care $\mathbf{( n = 3 2 8 )}$ \\
\hline \multicolumn{1}{l}{ Age group: } & $15(4)$ & $27(8)$ \\
\hline $15-19$ & $69(19)$ & $62(18)$ \\
\hline $20-24$ & $128(35)$ & $125(36)$ \\
\hline $25-29$ & $118(32)$ & $92(26)$ \\
\hline $30-34$ & $34(9)$ & $41(12)$ \\
\hline $35-39$ & $6(2)$ & $3(1)$ \\
\hline $40-44$ & & $187(53)$ \\
\hline No of pregnancies: & $198(54)$ & $95(27)$ \\
\hline One & $98(27)$ & $44(13)$ \\
\hline Two & $60(16)$ & $24(7)$ \\
\hline Three & $14(4)$ & $306(87)$ \\
\hline Four or more & & $40(11)$ \\
\hline Marital status: & $397(91)$ & $2(1)$ \\
\hline Married or cohabiting & $31(8)$ & $2(1)$ \\
\hline Single & $2(1)$ & $145(42)$ \\
\hline Widowed, divorced, or separated & $0(0)$ & $64(18)$ \\
\hline Other & & $141(40)$ \\
\hline Education: & $141(38)$ & \\
\hline Not completed high school & $143(39)$ & \\
\hline Completed high school & & \\
\hline Tertiary & & \\
\hline
\end{tabular}

Table 1 shows the demographic characteristics and number of pregnancies of women in the control and intervention groups. Table 2 shows the factors identified a priori as potential confounders for the study in each of the groups. Compared with Australia's perinatal statistics, except for number of births and education, the sample characteristics are similar to the national norms. Compared with the national statistics, our sample had a higher proportion of primiparous women $(53.5 \% v 39.7 \%)$ and a lower proportion of women with four or more births $(5.3 \% v 9.9 \%)$.

\section{Retention of women in the study}

Between being seen in hospital and the follow up telephone call at three months, 22 women each $(6 \%)$ dropped out of the intervention group and the control group. Sixty four women in the intervention group did not attend the follow up visit at eight weeks. As we are analysing by intention to treat, these 64 women were included in the outcome analyses.

\section{Continence status at three months}

At three months post partum, the prevalence of incontinence in the intervention group was $31.0 \%(108)$ and in the usual care group $38.4 \%$ (125) (difference 7.4\%

Table 2 Clinical characteristics of women in the intervention and control group at baseline. Values are numbers (percentages)

\begin{tabular}{lcc} 
& Intervention $(\mathbf{n}=\mathbf{3 4 8})$ & Usual care $(\mathbf{n}=\mathbf{3 2 8})$ \\
\hline Incontinent before recent pregnancy: & & \\
\hline Yes & $61(18)$ & $54(17)$ \\
\hline Incontinent immediately after giving birth: & $35(10)$ & $30(9)$ \\
\hline Yes & $23(7)$ & $13(4)$ \\
\hline Don't know & $31(9)$ & $29(9)$ \\
\hline Age over 36 years & $105(30)$ & $101(32)$ \\
\hline Body mass index overweight or obese ${ }^{*}$ & $233(66)$ & $204(63)$ \\
\hline Perineal tear with sutures, episiotomy, or both & $53(15)$ & $36(11)$ \\
\hline Joint hypermobility & $75(21)$ & $145(23)$ \\
\hline Marked abdominal striae & $54(44)$ &
\end{tabular}

${ }^{\star}$ Data are missing for 3 women in the intervention group and 8 women in the control group.
(95\% confidence interval $0.22 \%$ to $14.6 \%, \mathrm{P}=0.044$ ). Table 3 shows the results of the logistic regression analysis. After residual confounding was controlled for, the odds ratio of incontinence for women in the intervention group compared with the control group was 0.65 (0.46 to $0.91, \mathrm{P}=0.01)$. The experience of incontinence before the most recent pregnancy and continence status immediately after delivery also had an independent significant effect on continence status at three months.

At three month follow up a significantly lower proportion of women who had mixed symptoms (symptoms of stress incontinence together with symptoms of urge incontinence) had severe symptoms in the intervention group than in the control group (10.1\% (35 women) $v 16.8 \%$ (55 women); a difference of $6.7 \%(1.6 \%$ to $11.8 \%)(\mathrm{P}=0.01)$.

\section{Adherence to pelvic floor exercises}

The two groups differed significantly in regard to the performance of pelvic floor exercises three times per week or more $(\mathrm{P}=0.001)$. In the usual care group 189 women), $57.6 \% \quad(52.3 \%$ to $62.9 \%)$ and in the intervention group (292 women, $83.9 \% \quad(80.0 \%$ to $87.8 \%$ ) of women reported performing pelvic floor exercises at adequate levels, a difference of $26.3 \%$.

\section{Discussion}

This is the first study to show that an intervention delivered to women in the immediate and early post partum reduces the likelihood of urinary incontinence three months later. The finding that women in the intervention group were significantly more likely to be performing pelvic floor exercises at adequate levels during the three month period after giving birth strengthens the causal role of the intervention.

\section{Potential limitations}

Firstly, the results of the main effects of the intervention are of marginal statistical significance, with comparatively wide confidence intervals. When residual confounding was controlled for in the logistic regression, however, the strength of the association increased slightly. We analysed by intention to treat. It is possible that the effect would be strongest among women who participated in all components of the intervention. Secondly, we need to consider the external validity of the study, as the sample was drawn from only three hospitals. But these hospitals-urban public, urban private, and rural-served diverse population groups. Thirdly, the response rate indicated that only just over half of women who might have participated in the study actually did so. The fact that women were missed is a reflection of current practice in many maternity hospitals in Australia. Women are encouraged to leave hospital within hours of delivery, with home support provided by visiting midwives; women with private health insurance usually choose to convalesce in private hospitals.

We did not approach women who had had a stillbirth or a baby in neonatal intensive care, women who had a disability that meant that they could not perform pelvic floor exercises, women who were not residents of Australia, and women who could not speak English sufficiently to give consent. As $79 \%$ of the 
Table 3 Results of logistic regression predicting incontinence at three months after delivery

\begin{tabular}{|c|c|c|c|c|}
\hline Variables in order of entry & No of participants & $P$ value & Adjusted odds ratio (95\% CI) & $\begin{array}{l}\text { Crude odds ratio } \\
\text { (95\% CI) }\end{array}$ \\
\hline \multicolumn{5}{|l|}{ Group: } \\
\hline Control & 328 & & 1.00 & \\
\hline Intervention & 348 & 0.01 & 0.65 (0.46 to 0.91$)$ & $0.72(0.52$ to 0.99$)$ \\
\hline \multicolumn{5}{|l|}{ Continence status before pregnancy: } \\
\hline Continent & 561 & 0.0001 & 1.00 & \\
\hline Incontinent & 115 & & 2.53 (1.63 to 3.94$)$ & 2.89 (1.94 to 4.30$)$ \\
\hline \multicolumn{5}{|c|}{ Continence status immediately after giving birth: } \\
\hline Continent & 575 & & 1.00 & \\
\hline Incontinent & 65 & 0.005 & 2.09 (1.21 to 3.61$)$ & 2.24 (1.35 to 3.72$)$ \\
\hline Don't know & 36 & 0.002 & 2.88 (1.42 to 5.84$)$ & 2.72 (1.41 to 5.25$)$ \\
\hline Age: & & & 1.60 (0.91 to 2.82$)$ & 1.88 (1.10 to 3.20$)$ \\
\hline 35 years and younger & 616 & 0.106 & 1.00 & \\
\hline Over 35 years & 60 & & 1.60 (0.91 to 2.82$)$ & $1.88(1.10$ to 3.20$)$ \\
\hline \multicolumn{5}{|l|}{ Body mass index: } \\
\hline Normal and below & 427 & 0.269 & 1.00 & \\
\hline Overweight/obese & 238 & & 1.23 (0.85 to 1.79$)$ & 1.33 (0.96 to 1.86$)$ \\
\hline \multicolumn{5}{|l|}{ Perineal trauma: } \\
\hline Minor or none & 239 & 0.047 & 1.00 & \\
\hline Tear with sutures, episiotomy, or both & 437 & & 0.87 (0.60 to 1.26$)$ & $0.84(0.62$ to 1.16$)$ \\
\hline \multicolumn{5}{|l|}{ Joint hypermobility: } \\
\hline No & 587 & 0.512 & 1.00 & \\
\hline Yes & 89 & & 1.18 (0.72 to 1.92$)$ & $1.13(0.71$ to 1.80$)$ \\
\hline \multicolumn{5}{|l|}{ Abdominal striae: } \\
\hline None or mild & 528 & 0.758 & 1.00 & \\
\hline Marked & 148 & & 1.07 (0.70 to 1.64$)$ & $0.95(0.65$ to 1.40$)$ \\
\hline \multicolumn{5}{|l|}{ Instrumental delivery: } \\
\hline No & 299 & 0.983 & 1.00 & \\
\hline Any & 377 & & $1.00(0.70$ to 1.44$)$ & 0.89 (0.64 to 1.22) \\
\hline
\end{tabular}

women approached agreed to enter the study, however, bias due to non-consent was minimised.

Women were not blinded to whether they were in the intervention or the control group. They were, however, explicitly told that the study was not measuring their personal individual exercise practice in any punitive fashion but rather whether the intervention helped them to remember to do their pelvic floor exercises. In spite of this, women might have felt socially pressured to admit to exercise levels above those that they performed. Another consideration is that levels of pelvic floor exercise were measured by using self report, which could lead to social desirability bias in the intervention group. There are, however, few, if any, alternatives for monitoring the performance of this type of exercise accurately.

The study also had several strengths. Firstly, we used a randomised controlled design. Secondly, the sample size was sufficient to detect a difference of around $8 \%$ between groups as significant. Thirdly, the data were analysed by intention to treat. Randomised controlled trials are highly idealised and do not mirror real clinical practice. As this study set out to examine how effectively the exercise programme was adhered to, the lack of adherence to exercise by the women in this study gives a realistic outcome that mirrors the potential for the performance of pelvic floor exercises among women who have recently given birth.

The findings have several important implications. Firstly, many women experienced incontinence after delivery. The data from the usual care group show a prevalence of urinary incontinence of $38.4 \%$ among women who had forceps or ventouse deliveries or whose babies had a birth weight of $4000 \mathrm{~g}$ or more. Secondly, the intervention seemed to have most effect on women with severe mixed incontinence. Although it is difficult to offer a reason for this outcome, it is important to note that urinary incontinence was based on the symptoms experienced by the women in this study and no urodynamic assessments were carried out. These results could, however, be the effect of the information regarding good bladder habits that was given to women in the intervention group.

Thirdly, it is likely that the intervention was successful because it was based on established theories of behaviour change, incorporated known principles of anatomy and physiology, and included input from consumers in its development. Since dropout rates have been shown to be high among postpartum women performing pelvic floor exercises, the use of behavioural principles seems to have encouraged adherence to the exercise programme and the performance of such exercises. That the programme was designed to exercise specific muscles and fit in with the normal daily routine of the women may have added to its acceptability. The effect of these components in women who have given birth needs to be studied in the longer term, and follow up assessment is planned at 12 months post partum.

If this programme was disseminated among and taught to women by physiotherapists, this could result in the promotion of continence in the wider population. Although the intervention in this study was delivered by physiotherapists, who used their considerable specialist expertise in prescribing exercise programmes, other health professionals such as midwives and primary care physicians could be trained to carry out the different parts of the interventionmidwives immediately after the delivery and physicians or midwives at a postpartum visit. 


\section{What is already known on this topic}

Intensive pelvic floor exercise programmes can reduce urinary incontinence in selected groups of female patients

The effectiveness of interventions promoting continence in reducing urinary incontinence in the female population overall has not been investigated

Pelvic floor exercises are widely held to be an important component of continence promotion programmes

\section{What this study adds}

Continence promotion programmes delivered to a selected population are able to prevent urinary incontinence in that population

Few studies have examined the efficacy of compliance aiding strategies in helping women adhere to prescribed pelvic floor exercise programmes

Contributors: PC carried out the study as part of the research undertaken for her $\mathrm{PhD}$. JC was PC's PhD supervisor and is the guarantor for the study.

Funding: Medical Benefits Fund, Physiotherapy Foundation, and University of Newcastle Research Management Committee.

Competing interests: None declared.

1 Simeonova Z, Bengtsson C. Prevalence of urinary incontinence among women at a Swedish primary health care centre. Scand J Primary Healthcare 1990;8:203-6.

2 Nygaard I, DeLancey JOL, Arnsdorf L, Murphy E. Exercise and incontinence. Obstet Gynecol 1990;75:848-51.

3 Clark A, Romm J. Effect of urinary incontinence on sexual activity in women. J Reprod Med 1993;38:679-83.

4 Herzog AR, Fultz NH, Brock BM, Brown MB, Diokno AC. Urinary incontinence and psychological distress among older adults. Psychol Aging 1988:3:115-21.

5 Lagro-Janssen T, Smits A, VanWeel C. Urinary incontinence in women and the effects on their lives. Scand J Primary Health Care 1992;10:211-6.
6 Chiarelli P, Brown W, McElduff. Leaking urine: prevalence and associated factors in Australian women. Neurourol Urodynam 1999;18:567-77.

7 Hsu T. Impact of urinary incontinence on healthcare costs. J Am Geriatr Soc 1990;38:292-5.

8 Doran C, Chiarelli P, Cockburn J. Economic costs of urinary incontinence in community-dwelling Australian women. Med J Aust 2001;174:456-8.

9 Bo K, Talseth T. 5 year follow up of pelvic floor muscle exercise for treatment of stress urinary incontinence. Neurourol Urodynam 1994;13:374-6.

10 Hahn I, Milsom I, Ohlsson BL, Ekelund P. Pelvic floor training for genuine stress incontinence. Br J Urol 1993;72:421-7.

11 Foldspang A, Mommsen S, Durhuus J. Prevalent urinary incontinence as a correlate of pregnancy, vaginal childbirth and obstetric techniques. Am J Public Health 1999;89:209-12.

12 Persson J, Wolner-Hanssen P, Rydstroem H. Obstetric risk factors for stress urinary incontinence: a population based study. Obstet Gynecol 2000;96:440-5.

13 Viktrup L, Lose M, Rolff M, Barfoed K. The symptom of stress incontinence caused by pregnancy or delivery in primiparas. Obstet Gynaecol 1992;79:945-9.

14 Wilson PD, Herbison RM, Herbison GP. Obstetric practice and the prevalence of urinary incontinence three months after delivery. Br J Obstet Gynaecol 1996;103:154-61.

15 Miller Y, Chiarelli P, Brown W. Urinary incontinence across the lifespan. Neurourol Urodynam (in press).

16 Pocock SJ. Statistical aspects of a clinical trial design. The Statistician 1982;31(1):1-18

17 Cummings KM, Becker MH, Maile MC. Bringing the models together: an empirical approach to combining variables used to explain health actions. J Behav Med 1980;3:123-45.

18 Chiarelli P. What the experts said: developing a post partum continence promotion program. Aust Continence J 1999;5:41-2.

19 Chiarelli P, Cockburn J. The development of a physiotherapy continence promotion program using a customer focus. Aust I Physiother 1999;45:111-20.

20 International Continence Society. First report on the standardisation of lower urinary tract function. Urinary incontinence. Procedures related to the evaluation of urine storage: cystometry, urethral closure pressures, units of measurement. BrJ Urol 1976;48:39-42.

21 Gunthorpe W. The development of a GP-based treatment program for women with urinary incontinence [doctoral thesis]. Newcastle, 1998.

22 Chiarelli P, Campbell E. Incontinence during pregnancy. Prevalence and opportunities for continence promotion. Aust N Z J Obstet Gynaecol 1997;37:66-73.

23 Sandvik H, Hunskaar S, Seim A, Hermstad R, Vanvik A, Bratt H. Validation of a severity index in female urinary incontinence and its implementation in an epidemiological survey. J Epidemiol Comm Health 1993;47:497-9.

24 Uebersax JS, Wyman JF, Shumaker SA, McClish DK, Fantl JA. Short forms to assess life quality and symptom distress for urinary incontinence in women: the incontinence impact questionnaire and the urogenital distress inventory. Neurourol Urodynam 1995;14:131-9.

25 Sayer T. Stress incontinence of urine: a connective tissue problem? Physiotherapy 1994;80:143-4.

26 Sayer T, Dixon J, Hosker G, Warrell D. A study of paraurethral connective tissue in women with stress incontinence of urine. Neurourol Urodynam 1990;9:319-20.

(Accepted 29 November 2001) 